\title{
Student and Instructor Attitudes toward Responsibility of Learning and Teaching Essential Programs
}

\author{
Kaylee Boyd, Stacy Lee, and Jung Ha-Brookshire, University of Missouri, USA
}

Keywords: Responsibility, learning, teaching

Students who believe that they are responsible for learning are more confident and gain more esteem in their own learning (Halloran, 2008). However, many students believe that any new knowledge has to be taught, or it is the instructor's responsibility to teach every single element introduced during the class period (Bauman, 2003). On the other hand, instructors perceive that some information used in the course should not be the instructor's responsibility, but should be considered as a matter of ability to prepare for learning (Bauman, 2003). Consequently, there have been demonstrated disparities in student and instructor expectations of learning responsibilities, creating gaps in course material preparation and reducing productive class time (Pease, 2012).

Retail Math and Apparel Design courses are essential components to merchandising and product development majors. Several courses require students to use Excel or Illustrator programs. These are basic tools for teaching and learning math and design. Some students think that everything about these programs must be taught in class. At the same time, instructors may think that their job is to teach concepts, rather than software techniques. A gap in technology between students and instructors also exists in today's higher education, hindering the true potential of student learning outcomes. In this light, we explored the attitudes of students and instructors for teaching and learning responsibilities using Excel and Illustrator as examples.

To determine the direction of the study, three undergraduate students in a U.S. Midwestern university were interviewed about their feelings toward the class and about what they struggled with. According to these respondents, using Excel was the most challenging aspect of the Retail Math course. The purpose of Retail Math was not necessarily to teach Excel, but these preliminary interviews indicated that some students believe that the professor has a responsibility to teach how to use Excel during the class time. For product development or apparel design students, Illustrator is a comparable program in that it is necessary in many design classes. Similar gaps between learning and teaching responsibilities were expected, and the interview findings led to the next step of the research.

Next, we conducted a survey in a Midwestern university after receiving approval from the Institutional Review Board. A total of 37 different techniques, 17 specific to Excel and 20 specific to Illustrator adapted from Excel and Illustrator free training programs on campus, were presented to students; the survey asking for feedback regarding the responsibility levels of each technique. To measure expectations toward responsibility of learning among students, we targeted apparel merchandising and product development major students. Merchandising majors

Page 1 of 2 
were asked to fill out only the Excel section of the survey, while product development majors only completed the Illustrator section. A 5-Likert scale was used: 1 as "Mostly student's responsibility," to 5 as "Mostly instructor's responsibility." A total of 92 surveys were collected but 80 surveys were used for analysis. Respondents were $82 \%$ were either junior or seniors, while $10 \%$ were freshman or sophomores. Of the respondents, 66 reported as merchandising majors, and 8 were product development majors. To compare attitudes of learning and teaching responsibilities of students, instructors were also asked to participate in a survey, and 6 data responses were collected. Instructors were given a survey with the same questions.

For the Excel survey, the average student response to the questions about responsibility for learning specific Excel tasks was 3.06, while that of the instructors was 2.73. Although the results cannot be analyzed through t-test due to uneven sample sizes, some findings can be reported. This result indicated that on average, students believed that it is a nearly equal responsibility of both students and instructors to learn and teach various techniques of Excel, while instructors thought it is more of the students' responsibility. Specifically, students thought that the majority of Excel techniques must be taught in the classroom, while instructors thought that only six Excel techniques must be taught in class. They were: including entering a formula into a cell; using the $\$$ symbol to create an absolute reference in a cell; formatting values as currency, percentages, etc.; sorting and filtering data; applying conditional formatting to cells; and creating data tables. For the Illustrator survey, the results were the opposite. The average student response was 3.33, and that of instructor response was 4.23. That is, instructors felt that they are responsible for teaching all 20 Illustrator techniques. Why such gaps exist or not is not evident from this study.

These results suggest that instructors may want to consider setting clear requirements of student learning responsibilities, and possibly requiring students to take an assessment to test their knowledge of Excel or Illustrator prior to enrolling. Future research on how to set and communicate learning expectations between instructors and students would be helpful. This study can be improved by increasing the scale, and recruiting more participants, especially instructors.

\section{References}

Bauman, I. (2003). Responsibility in Instruction: Who is doing the learning here? Communications Studies, 54(2), 127-129.

Halloran, P., \& Halloran, P. (2008). The Practice of Personal Learning. 30 ${ }^{\text {th }}$ International Conference on Information Technology Interfaces, 129-134.

Pease, J. P. (2012). Sharing the Learning. Kappan Magazine, 94 (2), 36-41. 